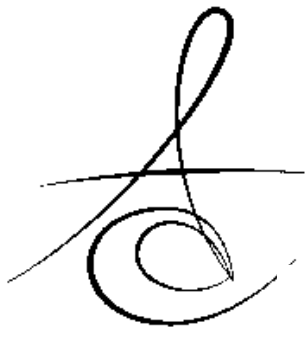

Yrd. Doç. Dr. Aslı PATIR MÜNEVVEROĞLU*

\section{ÇOCUKLARDA TÜM YÖNLERİYLE BRUKSİZM}

CHILDHOOD BRUXISM IN ALL ASPECTS

\author{
Makale Kodu/Article code: 2579 \\ Makale Gönderilme tarihi: $\quad 01.02 .2016$ \\ Kabul Tarihi: 10.06.2016
}

\section{öz}

Bruksizm; Amerikan Uyku Bozuklukları Birliği tarafından, diş sıkma ve diş gıcırdatmanın görüldüğü, çiğneme sisteminin periodik, kalıplaşmış hareket bozukluğu olarak tanımlamaktadır ve gece ya da gün boyunca oluşabilmektedir. Genellikle hastalar gün boyunca dişlerini sıkmakta; gece ise dişlerini gıcırdatmaktadır. Bruksizm ile ilgili çok sayıda çalışma yapılmasına ragmen, etiyolojisi tartışmalıdır. Çocuklarda görülme sıklığı \%14-20 arasında değişmektedir ve kız çocuklarında daha sık saptandığı bildirilmektedir. Son yıllarda, çocuklarda hayat kalitesi üzerindeki etkileri ve temporomandibular disfonksiyonlara neden olması nedeni ile bruksizme ilgi artışı söz konusu olmuştur.

Anahtar Kelimeler: Bruksizm, çocuk, etiyoloji, tedavi

\section{ABSTRACT}

American Sleep Disorders Association defined bruxism as a periodic, stereotyped movement disorder of the masticatory system involving tooth grinding or clenching during sleep. Bruxism can occur durind the day or night. Generally, patients clench their teeth throughout the day and gnash and clench them during sleep. It is a destructive habit that may result in tooth wear. Although research on bruxism is extensive, its etiology remains debatable. Reported prevalence in children ranges from $14 \%$ to $20 \%$, with girls apparently more frequently affected. In recent years, bruxism has become an increasing concern in children due to its negative effects on life quality and also for being considered an important risk factor for temporomandibular dysfunctions.

Keywords: Bruxism, child, etiology, treatment

\section{GİRİ̧̧ ÇOCUKLARDA TÜM YÖNLERİYLE BRUKSİZM}

Bruksizm; Amerikan Uyku Bozuklukları Birliği (American Sleep Disorders Association) tarafından, diş sıkma ve diş gıcırdatmanın görüldüğü, çiğneme sisteminin periodik, kalıplaşmış hareket bozukluğu olarak tanımlamaktadır. ${ }^{1,2}$ Diş gıcırdatma ve diş sıkma ile kendini gösteren olağan dışı artmış aktivite olarak da tanımlanan bruksizm, gece ya da gün boyunca oluşabilmektedir., ${ }^{3,-11}$ Diurnal bruksizm (Awake bruxism $(A B))$; gün boyu görülebilen yarı istekli diş sıkma aktivitesi olarak tanımlanmaktadır ve strese bağlı olarak gelişmektedir. Uyku bruksizmi (sleep bruxismSB), dişhekimliğinde, nadir görülen orofasiyal hareket olarak; uyku tıbbında ise parasomnia olarak tanımlanmaktadır ${ }^{8,12}$ ve primer olarak uykunun hızlı göz hareketi fazında (REM- rapid eye movement) saptanmaktadır. ${ }^{12} \mathrm{SB}$, ilk süt dişi sürdükten 1 yı sonra ortaya çıkabilmektedir ve genç populasyonda daha sık görülmektedir. ${ }^{11}$

\section{Çocuklarda bruksizm'in etyolojisi}

Bruksizmin etyolojisi multifaktöriyel olarak açıklanmaktadır. ${ }^{3,4,12-15}$ Bruksizmin, merkezi sinir sistemi tarafından düzenlendiği ancak periferal sinir sisteminin de bruksizm üzerinde etkisi olduğu bildirilmektedir. ${ }^{16}$ Bu durum, ağız alışkanlıklarının, temporomandibuler hastalıkların (TMD), maloklüzyonların, hipopnenin, yüksek endişe seviyelerinin, kişiliğin ve bunların yanında stresin periferal olarak bruksizmin ortaya

* İstanbul Medipol Üniversitesi Çocuk Diş Hekimliği i A D 
çıkmasında etki edebileceğini göstermektedir. Santral sinir sistemine giden motor uyarıya yanıt olarak dopamin nörotransmisyonunda değişiklik meydana gelmekte ve sonuçta dişler sıkılmakta ya da gıcırdatılmaktadır. 3,8,16-18 Bruksizmin etyolojisinde yer alan faktörler 3 grup altında incelenmektedir: ${ }^{18}$

1. Santral/patofizyolojik faktörler:

Patofizyolojik faktörler, bruksizmin oluşmasında rol oynamaktadır. ${ }^{19}$ Küçük çocuklarda bruksizmin mastikatör nöromuskuler sistemin gelişmesini tamamlaması sonucu oluştuğuna dair kanıtlar bulunmaktadır. Beyin kimyasındaki değişikliklerin (ör; asimetrik nigrostriatal dopaminerjik fonksiyon) bruksizmin etyolojisinde yer aldığı da bildirilmektedir. ${ }^{20}$ Yetişkinlerde ve adolesanlarda bruksizm ile ilişkili olan diğer patofizyolojik faktörler arasında sigara, alkol ve kanunsuz ilaç kullanımı, travma, hastalık ya da tıbbi müdahalenin yer aldığı da vurgulanmaktadır. 3,12

\section{Psikososyal faktörler:}

Bu faktörlerde stres ve kişilik özellikleri yer almaktadır. ${ }^{3}$ Lobbezoo ve ark. ${ }^{20}$, stres ve kişilik özelliklerinin bruksizmin etyolojisinde yer aldığını bildirmişlerdir. Ancak fizyolojik faktörlerin kesin etkisinin tartışmalı olduğu vurgulanmaktadır. ${ }^{21}$ Bu bulgular daha önce Kampe ve ark. ${ }^{22}$ tarafından da belirlenmiş ve bruksizm saptanan bir grup bireyde yüksek derecede anksiyete görüldüğü bildirilmiştir. Vanderas ve ark. ${ }^{23}$ çalışmalarında, stres ve anksiyetenin bruksizm ile direkt ilişkisi olduğunu, bu bireylerde emosyonel strese bağlı olarak yüksek katekolamin derecesi saptandığını bildirmişlerdir.

\section{Morfolojik faktörler:}

Bu faktörler arasında dental oklüzyon, orofasiyal iskelet anatomisi yer almaktadır. Daha önceki yıllarda, oklüzal değişikliklerin (ör; en geri kontakt noktası ve interkuspal pozisyondaki kayma) bruksizmin en sık görülen nedeni olduğu bildirilmiş ancak son yıllarda yapılan çalışmalarda ise, oklüzal kontaktların bruksizme neden olmadığı belirtilmiştir. ${ }^{3}$

Antunes ve ark. ${ }^{24}$ 3-6 yaşındaki çocuklarda bruksizm ile ilişkili faktörleri ve bruksizmin hayat kalitesi üzerine etkisini inceledikleri çalışmalarında, bruksizmin solunum problemleri, diş çürükleri ve maloklüzyon ile ilişkili olduğunu saptamışlar ve bruksizmin hayat kalitesi üzerinde etkisi olmadığını bildirmişlerdir.

Çocuklarda görülen bruksizm fizyolojik farklılık göstermektedir. Beyindeki dopamin seviyesi, ergenlik döneminde çok yüksek seviyelere ulaşıncaya kadar orantılı olarak artmakta ve ergenlik döneminde en üst seviyeye ulaştıktan sonra 30 yaşına kadar devamlı bir düşüş göstermektedir. ${ }^{25} \mathrm{Bu}$ durum, çocuklarda bruksizmin etyolojisi ile ilgili çalışmaları erişkinlerde yapılan çalışmalar ile karşılaştırılamaz hale getirmektedir. Mevcut literatürde yeterli bilimsel kesinlik olmadığı için çocuklarda yeni çalışmalar yapılması önem taşımaktadır. ${ }^{8}$

Çocuklarda, parmak emme, emzik emme, tırnak yeme gibi parafonksiyonel davranışların, şiddeti, frekansı ve süresinin yetişkin bireylerden daha fazla olduğu belirtilmektedir. Bu davranışların prevalansı ve insidansı yaşla birlikte azalsa da çocukluk döneminde bu davranışları gösteren çocuklarda, erişkinlik dönemlerinde de aynı davranışların görülebileceği düşünülmektedir. $^{8}$

Nöropsikolojik hastalıkların sıklıkla obstrüktif solunum hastalıkları (obstructive ventilatory diseaseOVD) ile ilişkili oldukları bildirilmektedir. OVD'nin en ciddi formu olan obstrüktif uyku apne sendromu (Obstructive sleep apnea syndrome-OSAS), hemoglobin desatürasyonuna eşlik eden tekrarlayan üst havayolu obstrüksiyonu atakları ile karakterize bir hastalık olarak tanımlanmaktadır. ${ }^{26}$ Yapılan çalışmalarda, OSAS'ın; dikkat eksikliği ve hiperaktivite (attentiondeficit/hyperactivity-ADHD) ve bruksizm ile ilişkisi araştırılmış, ancak bu çalışmalarda solunum ile bruksizm arasında bir ilişki olduğunu destekleyecek yeterli kanıt olmadığı bildirilmiştir. ${ }^{8,27}$

Bruksist çocuklarda, baş duruşunun hiperfleksiyonda olması ile birlikte daha ön ve aşağı yönlü baş postürleri ve kifotik boyun saptandığı bildirilmektedir. ${ }^{3,12} \mathrm{Bu}$ postür bruksist çocuklarda hava akımını etkileyebilir ve parafonksiyonlarının etyolojisinin bir parçası olabilmektedir. Ayrıca bu baş postürü, çiğneme kaslarında hipertrofi saptanan olgularda ve yüksek endişeye sahip bireylerde görülen postüre benzer niteliktedir ve her ikiside bruksizmin özellikleri arasında yer almaktadır. ${ }^{8,12}$

Bruksizmin herhangi bir parazit nedeni ile meydana geldiğine dair bir kanıt bulunmamaktadır. ${ }^{8}$ DiazSerrano ve ark. ${ }^{28}$, çalışmalarında bruksizm ve intestinal parazit infeksiyonu arasında herhangi bir ilişki olmadığını saptamışlardır. 
Bruksizm genetik faktörlere bağlı olabileceği gibi, ailesel öğrenilmiş bir alışkanlık da olarak ta ortaya çıkabilmektedir. Anketlerle veya diş aşınmalarını temel alarak yapılan tek yumurta ve çift yumurta ikizi çalışmaları, genetiğin bruksizmde belirleyici faktörlerden biri olduğunu göstermiştir. ${ }^{29}$ Tek yumurta ve çift yumurta ikizlerinde çiğneme fonksiyonu benzer uygunlukta bulunmuştur ${ }^{29}$. Bununla beraber başka bir ikiz çalışması, TME ile ilişkili işaret ve bulguların genetik bir temelinin olmadığını savunmaktadır. ${ }^{30}$

Finlandiya'da yapılan bir ikiz çalışmasında, çocukluktaki uyku bruksizminin çoğunlukla yetişkinlikte devam ettiği görülmüştür. ${ }^{31} \mathrm{Bu}$ çalışmanın sonucu, uyanık durumdaki ağız parafonksiyonu, diş sıkma ve gece diş gıcırdatmanın 20 yıl sonra devam edebildiği düşüncesiyle örtüşmektedir. ${ }^{30}$ Bruksizm görülen hastaların \% 20-\% 50'sinin, aile fertlerinden birinde çocukluğunda diş gıcırdatma hikayesi saptanmıştır. Gen bölümlerinin spesifik analizi kan alınarak yapılabildiği gibi, DNA örneklemesi yapılarak da bağlantı analizi oluşturulabilir. Bu kadar geniş uyku bruksizmi hastası içeren aile bulunması zor olduğundan, spesifik genlerin tanımlanması birkaç merkezli çalışma gerektirmektedir. $^{32}$

\section{Çocuklarda bruksizmin epidemiyolojisi}

Sıklıkla kişilerin hastalığa sahip olduğunun farkında olmaması ve tanı ile karışabilecek birçok faktör bulunması nedeniyle uyku bruksizminin prevalansını değerlendirmenin zor olduğu belirtilmektedir. ${ }^{8,28}$ Bruksizm, genç jenerasyonda daha sık görülmekte ve yaşla birlikte görülme sıklığı azalmaktadır. ${ }^{18,28,33}$ Bruksizm popülasyonda çok sık görüldüğü için normal bir davranış olarak kabul edilebilmekte ancak, hastada şiddetli ağız-diş problemi görüldüğünde, ses aile bireylerini rahatsız ettiğinde, uyku etkilendiğinde ya da ağrı oluştuğunda patolojik bir boyut kazandığı bildirilmektedir. ${ }^{34}$ Uyku bruksizminin çocukların \%14-20'sinde görüldüğü belirtilmek ile birlikte ${ }^{35}$; Machado ve ark. ${ }^{36}$ çocuklarda saptanan bruksizm ile ilgili çok az sayıda çalışma olduğunu ve standart tanı kriterleri kullanımadan yapılan bu çalışmalarda çok farklı sıklık değerleri elde edildiğini bildirmiştir.

\section{Çocuklarda bruksizmin tanısı}

Uyku ile ilişkili bruksizm, Uluslararası Uyku Bozuklukları Sınıflandırıması'nda Uyku ile ilişsili Hareket Bozuklukları alt grubunda yer almaktadır. ${ }^{37}$ Tanısı klinik olarak kolaylıkla konulabilmektedir. Tanı kriterlerinde, uyku sırasında düzenli ya da geçici olarak diş gıcırdatma sesinin duyuluyor olması gereklidir; buna eşlik eden uykuda diş gıcırdatmasına bağlı anormal diş aşınmasının varlığı ya da sabah çene ağrısı, temporal baş ağrısı, uyanırken çenede kilitlenme ve ağrı gibi klinik şikayetlerin varlığı gerekmektedir. Polisomnografi (PSG) tetkiki, uyku ile ilişkili bruksizm tanısında en sık kullanılan yöntemdir. Yapılan PSG uygulamasına ek olarak Masseter Kas Elektromiyografi (EMG) kayıtlaması ile birlikte ses kaydı özellikle önerilmektedir. Uyku süresince, masseter kası yüzeyel EMG kayıtlarında fazik kas kasılmaları ya da tonik kasılma olarak izlenen ritmik mastikatör kas aktivitesi, diş gıcırdatma sesi ile birlikte kesin tanı koydurucudur. ${ }^{38}$

Yapılan literatür araştırmaları sonucunda, bruksizm tanısı koymak için uygulanan dişlerdeki aşınma, anksiyete, temporomandibuler hastalıklar vb. yöntemlerin büyük çoğunluğunun indirekt yöntemler olduğu bildirilmektedir. Ayrıca önemli olan noktanın, bu ölçümlerin her zaman bruksizm ile ilişkili olmadığına ve bu nedenle tanının atlanabileceği ya da yalancı pozitif veya yalancı negatifliklerle karşılaşılabileceği vurgulanmaktadır. ${ }^{8}$ Ancak, PSG nin güvenilir bir yöntem olmasına rağmen sadece bruksizmin aktif döneminde etkili olduğu; bu nedenle aktif fazda olmayan bir günde uygulandığında tanının yanlış olabileceği bildirilmektedir. ${ }^{35}$ Tüm bu nedenlerle, gece bruksizmi tanısını koymada en güvenilir yöntemin ebeveynlerden veya bakıcılardan alınan bilgiler olduğu vurgulanmaktadır. Bu yöntemin ana sorunu, çocukların büyük çoğunluğunun ebeveynleri ile birlikte veya onlara yakın uyumamalarıdır, bu nedenle ebeveynler her zaman durumdan haberdar olmamaktadır. Diğer bir sorun gündüz bruksizmidir. Yapılan çalışmalar gündüz bruksizminin bilinçli yapılan bir davranış olduğunu göstermektedir, ancak küçük çocuklar ağızları ile ne yaptıklarının farkında olmamaktadır. ${ }^{8}$

\section{Çocuklarda bruksizm tedavisi}

Bruksizm tedavisinde kullanılan yöntemler:

Davranış yönetimi: Hastaya dilini, dişlerini ve dudaklarını nasıl konumlandıracağını öğretmek

* Stres yönetimi

* Yaşam şartlarının değiştirilmesi

* Gelişmiş başa çıkma yöntemleri ${ }^{39}$ 
Dişlerdeki aşınma: Aşınma saptanan dişlerde restorasyon materyali olarak direkt hibrit kompozit materyallerin uygulanması önerilmektedir. ${ }^{39}$ Hibrit kompozit materyaller, güçlendirilmiş organik matriks içerikleri nedeni ile normal oklüzal kuvvet ile karşılaşan diş yüzeylerinin tekrar oluşturulmasında etkili materyalledir. ${ }^{40}$ Dişlerdeki aşınmalar bruksizm nedeni ile oluşabileceği gibi, asitli beslenme, gastrik reflü ve sigara kullanımı sonucunda da ortaya çıkabilmektedir. ${ }^{39}$

Oklüzal splint: Dişhekimliğinde bruksizm tedavisinde en sık kullanılan yöntem sert oklüzal splint uygulamasıdır. ${ }^{41,42}$ Çocuklarda splint kullanımının üst çenede alveol kemik büyümesini sınılandırıp sınırlandırmadığını ve çocuklarda bruksizm semptomlarının tedavisinde faydalı olup olmadığının değerlendirildiği bir çalışmada; oklüzal splint kullanımının üst çenede kemik gelişimini sınırlandırmadığı ancak bruksizm semptomlarının azalmasına da faydalı olmadığı sonucuna varıldığı bildirilmektedir. ${ }^{42}$

Restrepo ve ark. ${ }^{41}$ bruksist çocuklarda oklüzal splint uygulamasının TMD, dişlerde aşınma ve anksiyete üzerine etkisini araştırdıkları çalışmalarında rijit oklüzal ısırma plaklarının bruksizm belirtilerinin azalmasında yeterli olmadığını ancak ağız açma sırasında oluşan deviasyonu azalttığını saptamışlardır.

İlaç tedavisi: Benzodiazepin, kas gevşetici benzeri ilaçlar erken dönemde, ağrı olduğunda etkili olabilmektedir. Akut klonazepam tedavisi sadece bruksizm değerlerini değiştirmemekte uyku kalitesini de arttırmaktadır. ${ }^{40}$

Çeşitli lokal uygulamaların da tedavi amacı ile uygulanabileceği vurgulanmaktadır. Çiğneme kaslarının hareketleri geceleri artabilen bir refleks meydana getirebileceği için sakızdan kaçınmak gerektiği bildirilmektedir. Yastıksız uyumak daha iyi bir vücut şekli sağlayacağından üst havayollarının doğru boyutlarda kalmasını sağlamaktadır. ${ }^{43}$ Ayrıca, sıcak ve ıslak kompres uygulamasının da uyku öncesi kasların gevşemesine yardımcı olabileceği belirtilmektedir. ${ }^{8}$

Uyku bruksizmi, uyku alışkanlıkları ile yakından ilişkilidir. Uyurken televizyon seyreden ve radyo dinleyen çocuklar bruksizme daha yatkın oldukları ve daha fazla baş ağrısı çektikleri belirtilmektedir. Bu nedenle, çocukların gün içinde en az bir kez kısa bir süre uyumaları gerektiği, uykuya dalarken televizyon izlemek yerine ebeveynlerinin onlara yüksek sesle kitap okumalarının ve çocukların yalnız uyumalarının önemli olduğu vurgulanmaktadır. ${ }^{44,45}$

\section{SONUÇ}

Bruksizm, yaş gözetmeksizin hemen her yaşta ortaya çıkabilmektedir ve gün geçtikçe bruksizm şikayeti ile başvuran çocuk hasta sayısında artış olmaktadır. Bu nedenle, bruksizmin etiyolojisini, risk faktörlerini ve klinik özelliklerinin ayrıntılı değerlendirildiği çok sayıda epidemiyolojik araştırma yapılması gerekmektedir. Ayrıca bu parafonksiyonel alışkanlığın tedavisinde diş hekimleri özellikle pedodontistler ağız bulgularına bağlı olarak tanı koyan ilk kişiler olmaktadır ve ebeveynleri bu konuda uyararak çocuğun sağlığına kavuşmasında önemli rol almaktadır.

\section{KAYNAKLAR}

1. Lopez-Perez R, Lopez-Morales P, Borges-Yanez SA, Maupome G, Pares-Vidrio G. Prevalence of bruxism among Mexican children with Down syndrome. Down Syndrome Research and Practice 2007;12:45-9.

2. Junqueira $T H$, Nahás-Scocate $A C$, Valle-Corotti KM, Conti AC, Trevisan S. Association of infantile bruxism and the terminal relationships of the primary second molars. Braz Oral Res 2013;27:427.

3. Quintero Y, Restrepo CC, Tamayo V, Tamayo M, Velez AL, Gallego G, Pelaez-Vargas A. Effect of awareness through movement on the head posture of bruxist cildren. J Oral Rehabil 2009;36:18-25.

4. Restrepo CC, Pelaez A, Alvarez E, Paucar C, Abad P. Digital imaging of patterns of dental wear to diagnose bruxism in children. Int J Paediatr Dent 2006; 16:278-85.

5. Ferini FRD, Marba STM, Gaviao MBD. Oral conditions in very low and extremely low birth weight children. J Dent Child 2008;75:235-42.

6. Muthu MS, Prathibha KM. Management of a child with autism and severe bruxism: A case report. J Indian Soc Pedod Prevent Dent 2008;82-4.

7. Bedi S, Sharma A. Management of temporomandibular disorder associated with bruxism. J Indian Soc Pedod Prevent Dent 2009;27;4:253-5 
8. Paesani DA. Bruxism: Theory and Practice. Quintessence Publishing. 2 ed. London:2011 p. 111-8.

9. Ferreira-Bacci Ado V, Cardoso CL, Díaz-Serrano KV. Behavioral problems and emotional stress in children with bruxism. Braz Dent J 2012;23:24651.

10. Ghafournia M, Hajenourozali Tehrani M. Relationship between Bruxism and Malocclusion among Preschool Children in Isfahan. J Dent Res Dent Clin Dent Prospects 2012;6:138-42.

11. Herrera M, Valencia I, Grant M, Metroka D, Chialastri A, Kothare SV. Bruxism in children: Effect on sleep architecture and daytime cognitive performance and behaviour. Sleep 2006;29:11438.

12. Velez AL, Restrepo CC, Pelaez-Vargas A, Gallego GJ, Alvarez E, Tamayo V, Tamayo M. Head posture and dental wear evaluation of bruxist children with primary teeth. J Oral Rehabil 2007;34:663-70.

13. Restrepo CC, Sforza C, Colombo A, Pelaez-Vargas A, Ferrario VF. Palate morphology of bruxist children with mixed dentination. A pilot study. J Oral Rehabil 2008;35:353-60.

14. Grechi TH, Trawitzki LVV, Felicio CM, Valera FCP, Alnselmo-Lima WT. Bruxism in children with nasal obstruction. Int J Pediatr Otorhinolaryngol 2008;72:391-6.

15. Fonseca CME, dos Santos MBF, Consani RLX, dos Santos JFF, Marchini L. Incidence of sleep bruxism among children in Itanhandu, Brazil. Sleep Breath 2011;15:215-20.

16. Lobbezoo F, Naeije M. Bruxism is mainly regulated centrally, not peripherally. J Oral Rehabil 2001 Dec;28:1085-91.

17. Restrepo CC, Sforza C, Colombo A, Pelaez-Vargas A, Ferrario VF. Palate morphology of bruxist children with mixed dentition. A pilot study. J Oral Rehabil 2008;35:353-60.

18. Barbosa Tde S, Miyakoda LS, Pocztaruk Rde L, Rocha CP, Gavião MB. Temporomandibular disorders and bruxism in childhood and adolescence: review of the literature. Int J Pediatr Otorhinolaryngol 2008;72:299-314.
19. Macaluso GM, Guerra P, Di Giovanni G, Boselli M, Parrino L, Terzano MG. Sleep bruxism is a disorder related to periodic arousals during sleep. J Dent Res 1998;77:565-73.

20. Lobbezoo F, Van Der Zaag J, Naeije M. Bruxism; its multiple causes and its effects on dental implants-an updated review. J Oral Rehabil 2006;33:293-300.

21. Restrepo CC, Alvarez E, Jaramillo C, Velez C, Valencia I. Effects of psychological techniques on bruxism in children with primary teeth. J Oral Rehabil 2001;28:354-60.

22. Kampe T, Edman G, Bader G, Tagdae T, Karlsson S. Personality traits in a group of subjects with long-standing bruxing behaviour. J Oral Rehabil 1997;24:588-93.

23. Vanderas AP, Papagiannoulis L. Multifactorial analysis of the aetiology of craniomandibular dysfunction in children. Int J Paediatr Dent 2002;12:336-46.

24. Antunes LA, Castilho T, Marinho M, Fraga RS, Antunes LS. Childhood bruxism: Related factors and impact on oral health-related quality of life. Spec Care Dentist 2016;36:7-12.

25. Vanderas AP, Menenakou $M$, Kouimtzis $T$, Papagiannoulis L. Urinary catecholamine levels and bruxism in children.J Oral Rehabil 1999;26:103-10.

26. Haycock JW, Becker L, Ang L, Furukawa Y, Hornykiewicz O, Kish SJ. Marked disparity between age-related changes in dopamine and other presynaptic dopaminergic markers in human striatum. J Neurochem 2003;87:574-85.

27. Brunetti L, Rana S, Lospalluti $M L$, Pietrafesa $A$, Francavilla R, Fanelli M, Armenio L. Prevalence of obstructive sleep apnea syndrome in a cohort of 1,207 children of southern Italy. Chest 2001;120:1930-5.

28. Diaz-Serrano KV, da Silva CBA, Albuquerque $S$, Saraiva MCP, Nelson-Filho $P$. Is there an association between bruxism and intestinal parasitic infestation in children? ] Dent Child 2008; 75: 276-9.

29. Michalowicz BS, Pihlstrom BL, Hodges JS, Bouchard TJ, Jr. No heritability of temporomandibular joint signs and symptoms. J Dent Res 2000;79:1573-8.

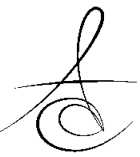


30. Hublin C, Kaprio J, Partinen M, Koskenvuo M. Sleep bruxism based on self-report in a nationwide twin cohort. J Sleep Res 1998;7:61-7.

31. Carlsson GE, Egermark I, Magnusson T. Predictors of bruxism, other oral parafunctions, and tooth wear over a 20-year follow-up period. J Orofac Pain 2003;17:50-7.

32. Lavigne GJ, Khoury S, Abe S, Yamaguchi T, Raphael K. Bruxism physiology and pathology: an overview for clinicians. J Oral Rehabil 2008;35:476-94.

33. Strausz T, Ahlberg J, Lobbezoo F, Restrepo CC, Hublin $C$, Ahlberg K, Könönen M. Awareness of tooth grinding and clenching from adolescence to young adulthood: a nine-year follow-up. J Oral Rehabil 2010;37:497-500.

34. Laberge L, Tremblay RE, Vitaro F, Montplaisir J. Development of parasomnias from childhood to early adolescence. Pediatrics $2000 ; 106: 67-74$.

35. Trindade Mde $O$, Rodriguez AG. Polysomnographic analysis of bruxism. Gen Dent 2014;62:56-60.

36. Machado E, Dal-Fabbro C, Cunali PA, Kaizer OB. Prevalence of sleep bruxism in children: a systematic review. Dental Press J Orthod 2014;19:54-61.

37. American Academy of Sleep Medicine. International classification of sleep disorders, 3 ed. IL: American Academy of Sleep Medicine, Darien: 2014.

38. Şenel GB, Dede HÖ, Karadeniz D. Uykuda Diş Gıcırdatma Tedaviye Dirençli ise...J Turk Sleep Med 2015; 2: 42-3.

39. Andréa G, Viviane $S$, Lucianne, Bruxism in children: A warning sign for psychological problems: J Can Dent Assoc 2006; 72: 155-60.

40. Gupta B, Marya CM, Anegundi R. Childhood bruxism: a clinical review and case report. West Indian Med J 2010;59:92-5.

41. Restrepo CC, Medina I, Patiño I. Effect of occlusal splints on the temporomandibular disorders, dental wear and anxiety of bruxist children. Eur J Dent 2011;5:441-50.

42. Hachmann A, Martins EA, Araujo FB, Nunes R. Efficacy of the nocturnal bite plate in the control of bruxism for 3 to 5 year old children. J Clin Pediatr Dent 1999;24:9-15.
43. Shetty S, Pitti V, Satish Babu CL, Surendra Kumar GP, Deepthi BC. Bruxism: a literature review. J Indian Prosthodont Soc 2010;10:141-8.

44. Zarowski M, Młodzikowska-Albrecht J, Steinborn B. The sleep habits and sleep disorders in children with headache. Adv Med Sci 2007;52:194-6.

45. Simões-Zenari M, Bitar ML. Factors associated to bruxism in children from 4-6 years. Pro Fono 2010; 22:465-72.

\section{Yazışma Adresi}

Yrd. Doç. Dr. Aslı Patır Münevveroğlu

Mega Medipol Hastaneler Kompleksi

Göztepe, Metin Sk. No:4,

34214 Bağcılar/İstanbul

05322301819

e-mail: apatir@medipol.edu.tr 